\title{
\begin{tabular}{l|l} 
Mibraries & DSpace@MIT
\end{tabular}
}

\author{
MIT Open Access Articles
}

\section{Heat Transfer Enhancement in Microchannel Flow: Presence of Microparticles in a Fluid}

The MIT Faculty has made this article openly available. Please share how this access benefits you. Your story matters.

Citation: Alquaity, Awad B. S., Salem A. Al-Dini, Evelyn N. Wang, Shahzada Z. Shuja, Bekir S. Yilbas, and Karl J. Suabedissen. "Heat Transfer Enhancement in Microchannel Flow: Presence of Microparticles in a Fluid." Proceedings of the ASME 2010 3rd Joint US-European Fluids Engineering Summer Meeting and 8th International Conference on Nanochannels, Microchannels, and Minichannels FEDSM-ICNMM2010, 1-5 August, 2010, Montreal, Quebec, Canada, ASME, 2010. (c) 2010 by ASME.

As Published: http://dx.doi.org/10.1115/FEDSM-ICNMM2010-30921

Publisher: ASME International

Persistent URL: http://hdl.handle.net/1721.1/120353

Version: Final published version: final published article, as it appeared in a journal, conference proceedings, or other formally published context

Terms of Use: Article is made available in accordance with the publisher's policy and may be subject to US copyright law. Please refer to the publisher's site for terms of use. 


\title{
FEDSM-ICNMM2010-१००००
}

\section{HEAT TRANSFER ENHANCEMENT IN MICROCHANNEL FLOW: PRESENCE OF MICROPARTICLES IN A FLUID}

\author{
Awad B.S. Alquaity ${ }^{1}$, Salem A. Al-Dini ${ }^{1}$, Evelyn N. Wang ${ }^{2}$, Shahzada Z. Shuja ${ }^{1}$ \\ Bekir S. Yilbas ${ }^{1}$, Karl J. Suabedissen ${ }^{2}$ \\ Department of Mechanical Engineering \\ ${ }^{1}$ K.F.U.P.M. Dhahran 31261, Kingdom of Saudi Arabia \\ ${ }^{2}$ M.I.T., Cambridge, MA, U.S.A
}

\section{ABSTRACT}

In the present study, a numerical model was developed for laminar flow in a microchannel with a suspension of microsized phase change material (PCM) particles. In the model, the carrier fluid and the particles are simultaneously present, and the mass, momentum, and energy equations are solved for both the fluid and particles. The particles are injected into the fluid at the inlet at a temperature equal to the temperature of the carrier fluid. A constant heat flux is applied at the bottom wall. The temperature distribution and pressure drop in the microchannel flow were predicted for lauric acid microparticles in water with volume fractions ranging from 0 to $8 \%$. The particles show heat transfer enhancements by decreasing the temperature distribution in the working fluid by $39 \%$ in a $1 \mathrm{~mm}$ long channel. Meanwhile, particle blockage in the flow passage was found to have a negligible effect on pressure drop in the range of volume fractions studied. This work is a first step towards providing insight into increasing heat transfer rates with phase change-based microparticles for applications in microchannel cooling and solar thermal systems.

\section{INTRODUCTION}

Heat transfer enhancement is important for variety of applications, including microchannel cooling and solar thermal energy conversion, among others. A promising method to enhance heat transfer rates is by introducing a fluid with particles that undergo phase-change in a flow system, such as in a microchannel flow. In this case, the momentum and energy exchange between the fluid and particles determines the heat transfer enhancement. Therefore, an investigation to quantitatively determine the heat transfer increases in a microchannel flow with particles become essential.

Significant efforts have focused on using PCMs for heat transfer enhancements in the past decade [1-7]. In particular, numerical studies have used different modeling frame works to examine heat transfer performance. Kondle numerically studied heat transfer characteristics of PCMs in a laminar flow for circular and rectangular microchannels [1]. The carrier fluid and particles were modeled as a bulk fluid and a specific heat model was used for the phase change of particles. The Nusselt number was found to be higher for the constant axial heat flux with constant peripheral temperature boundary condition 
compared to that corresponding to the constant heat flux with variable peripheral temperature. A similar specific heat model was used tomodel phase change of particles by $\mathrm{Hu}$ and Zhang [2] for the flow of PCM slurries in a circular tube with constant heat flux. Hao and Tao evaluated the performance of liquid flow with PCM particles in circular microchannels [3]. The conservation equations for the particle and liquid phase were solved separately while considering the effects of particleparticle interaction and the particle depletion boundary near the wall. A particular Reynolds number and wall heat flux was found to achieve maximum heat transfer enhancement with PCM particles. Al-Hallaj performed a three-dimensional numerical study on the performance of microchannel heat sinks using micro-encapsulated PCMs and considered the thermal resistance of the heat sink walls while taking temperature dependent physical properties for the PCM slurry [4]. In addition to the modeling efforts, significant experimental work has also been performed to examine heat transfer enhancements using PCM particles. Wang studied heat transfer in microencapsulated PCM suspension for a laminar flow through a circular tube under a constant heat flux, where a new expression for the Stefan number was developed [5]. Niu [6] studied the micro-encapsulated slurries in a horizontal circular tube by varying the mass fractions of slurries from $5 \%$ to $27.6 \%$. A new correlation for heat transfer coefficients for laminar flow slurries in a horizontal circular tube was developed. Yamagishi [7] studied the heat transfer enhancement using micro-encapsulated PCM slurry in a circular tube with uniform heat flux for both laminar and turbulent flows. As the particle volume fraction was increased, the flow regime changed from turbulent to laminar. While significant studies have been performed in the past, a model that provides insight into how various parameters affect heat transfer performance is needed, that will also guide future experiments.

TABLE 1. THERMOPHYSICAL PROPERTIES OF CARRIER FLUID AND PCM PARTICLES

\begin{tabular}{|c|c|c|c|}
\hline Fluid & Density & Specific Heat & Latent Heat \\
$\mathrm{kg} / \mathrm{m}^{3}$ & $\mathrm{~kg} * \mathrm{~K}$ & $\mathrm{~kJ} / \mathrm{kg}$ \\
\hline Water & 998.2 & 4.182 & - \\
\hline $\begin{array}{c}\text { Particle } \\
\text { (Solid) }\end{array}$ & 880 & 1.76 & 211 \\
\hline $\begin{array}{c}\text { Particle } \\
\text { (Liquid) }\end{array}$ & 880 & 2.27 & - \\
\hline
\end{tabular}

In this work, we seek to develop a unified model that can provide design guidelines for PCMs in microchannels based on PCM particle volume fractions, different PCM particle and carrier fluid properties, and various microchannel geometries.
We initiate these efforts by developing a numerical model using an Euler-Lagrangian approach to investigate the effect of increasing PCM particle volume fraction in a microchannel. We use water as the carrier fluid and lauric acid as the PCM particles with different volume concentrations ranging from 0 to $8 \%$. The thermophysical properties of both the carrier fluid and the PCM were assumed to be constant during simulations and are given in Table 1 . The model currently neglects particleparticle interaction effects.

\section{MODEL FRAMEWORK}

A schematic of the microchannel for the model is shown in Fig.1. A microchannel of constant height $(50 \mu \mathrm{m}, \mathrm{H})$, length (1000 $\mu \mathrm{m}, \mathrm{A})$ and width $(2000 \mu \mathrm{m}, \mathrm{B})$ was defined in the FLUENT $^{\mathrm{TM}}$ simulations. The carrier fluid with micron-sized particles of $1 \mu \mathrm{m}$ diameter enters the microchannel at a temperature just below the melting temperature of the particles. A constant heat flux is applied at the bottom wall, which heats up the carrier fluid and particles. After traversing a certain length of the microchannel, the particles undergo phase change. The phase change of the particles plays an important role in decreasing the bulk temperature change of the suspension as compared to the case with no phase change and thereby increases the thermal storage capacity of the suspension, and effective heat transfer coefficient.

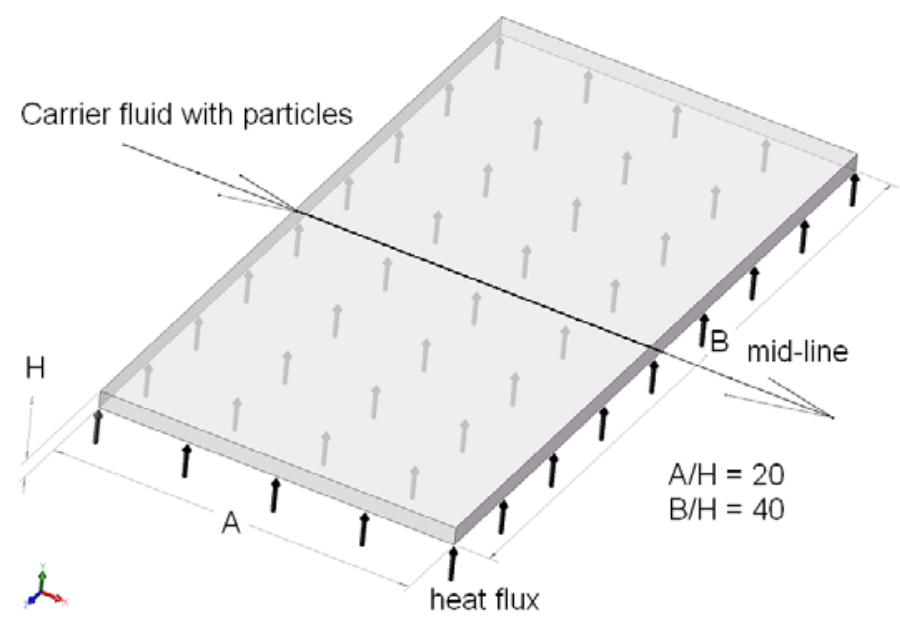

Figure 1. Geometry and flow direction in the microchannel used in the FLUENT simulations.

The flow is assumed to be steady and incompressible with constant properties. The equations governing laminar flow for the carrier fluid are shown below:

Continuity equation

$$
\nabla \cdot \vec{v}=0
$$


Momentum equation

$$
\nabla \cdot(\rho \overrightarrow{v v})=-\nabla p+\mu \nabla^{2} v+\vec{F}
$$

Energy equation

$$
\nabla \cdot(\vec{v}(\rho E+p))=\nabla \cdot(k \nabla T+(\bar{\tau} \cdot \vec{v}))+S
$$

The particles are injected uniformly at the inlet of the microchannel. The trajectory of the particles in the flow domain is obtained by integrating the force balance on the particle. The forces acting on the particle are the drag force and the virtual mass force [9]. The force balance equating the inertia of the particle to the forces in the $\mathrm{x}$-direction (in Cartesian coordinates) is given below:

$$
\frac{d v_{P}}{d t}=F_{D}\left(v-v_{P}\right)+F_{x}
$$

where $F_{D}$ is the drag force per unit particle mass and $F_{x}$ is the virtual mass force per unit mass acting on the particle and are given respectively as:

$$
\begin{gathered}
F_{D}=\frac{18 \mu}{d_{P}^{2} \rho_{P} C_{c}} \\
F_{x}=\frac{1}{2} \frac{\rho}{\rho_{P}} \frac{d\left(v-v_{P}\right)}{d t} \\
C_{c}=1+\frac{2 \lambda}{d_{P}}\left[1.257+0.4 e^{-\left(1.1 d_{P} / 2 \lambda\right)}\right]
\end{gathered}
$$

where $\lambda$ is the molecular mean free path. The Cunningham's correction factor, $C_{c}$, is taken as for continuum flows. The momentum transfer from the fluid to the particles is obtained by computing the change in momentum of the particle as it passes through each control volume as given below:

$$
\vec{F}=\sum\left(F_{D}+F_{x}\right) \dot{m}_{P} \Delta t
$$

The momentum transfer appears as a sink/source in the momentum equation for the carrier fluid. The heat transfer from the carrier fluid to the particles is obtained by computing the change in thermal energy of a particle as it passes through each control volume as given below:

$$
S=m_{\text {Pin }} \int_{T_{r}}^{T_{\text {in }}} C_{p} d T-m_{\text {Pout }} \int_{T_{r}}^{T_{\text {out }}} C_{p} d T
$$

The heat transfer term in the above equation appears as a source or sink term in the energy equation for the carrier fluid.

In order to account for the phase change of the particles, a specific heat model is used [1]. In the specific heat model, the phase change of particles is modeled by varying the specific heat capacity of the particles between the solidus and the liquidus temperatures. The melting temperature of lauric acid is $317.2 \mathrm{~K}$. In the present study, the melting range of PCM particles is assumed to $317-320 \mathrm{~K}$. The equations used for specific heat capacity are given below:

For $T_{P}<T_{\text {solidus }}$

$$
C_{P}=C_{P, S}
$$

For $T_{\text {solidus }}<T_{P}<T_{\text {liquidus }}$

$$
C_{P}=C_{P, S}+\frac{L}{T_{\text {solidus }}-T_{\text {liquidus }}}
$$

For $T_{P}>T_{\text {liquidus }}$

$$
C_{P}=C_{P, L}
$$

The flow within the microchannel is assumed to be hydrodynamically fully developed. In order to obtain the developed flow profile at the inlet, repeated simulations are performed without particles and heat transfer. The fully developed velocity profile is extracted at the outlet, and then subsequently applied as an inlet boundary condition.

An average velocity of $0.1 \mathrm{~m} / \mathrm{s}$ for both the carrier fluid and the particles is prescribed at the inlet $(\operatorname{Re}=7.65)$. Thus, the mass flow rate of the particles is calculated based on the particles volume fraction and inlet average velocity. The temperature of the particles and carrier fluid is $315 \mathrm{~K}$ at the inlet, which is initially less than the melting temperature of the particles. A constant heat flux of $120 \mathrm{~W} / \mathrm{cm}^{2}$ is applied at the bottom wall of the microchannel.

At the outlet, an outflow boundary condition is considered. The outflow boundary condition assumes zero diffusion fluxes in the direction normal to the exit plane for all flow variables (i.e., the velocity and temperature) except pressure. Outflow boundary conditions incorporated in FLUENT are used to model flow exits where the details of the flow velocity and pressure are not known prior to the solution of the flow problem [9]. In this case, the zero diffusion flux condition applied at outflow cells means that the conditions of the outflow plane are extrapolated from within the domain and have no impact on the upstream flow [9]. The zero diffusion flux condition can be used when the velocity and temperature 
profiles are fully-developed. In this work, the temperature profiles becomes fully developed at approximately $\mathrm{x}=0.8 \mathrm{~mm}$. While there does not appear to have a significant effect at the upstream temperature profiles due to the outflow boundary condition, the convective boundary condition would be most appropriate for the temperature at the exit of the channel when the total length of the channel is considered in this study.

\section{NUMERICAL SOLUTION}

A square grid with an aspect ratio of 1 is defined for the flow domain. The control volume approach is used in the numerical scheme. All variables are computed at each grid point except the velocities, which are determined midway between the grid points.

A staggered grid arrangement is used in the present study, which links the pressure through the continuity equation and is known as SIMPLE algorithm [8]. This iterative process is used for convergence. The pressure relationship between continuity and momentum is established by transforming the continuity equation into a Poisson equation for pressure. The convergence criterion for the scaled residuals is set to $10^{-6}$.

\section{TABLE 2.COMPARISON BETWEEN 2D AND 3D SIMULATIONS}

\begin{tabular}{|c|c|c|}
\hline & $2 \mathrm{D}$ & $\begin{array}{c}3 \mathrm{D} \\
(2 \mathrm{~mm} \text { width })\end{array}$ \\
\hline$\frac{\Delta P}{P}$ & 1.00104 & 0.972474 \\
\hline$\frac{\Delta T}{T}$ & 0.000867 & 0.00078 \\
\hline
\end{tabular}

We compare results of $2 \mathrm{D}$ and $3 \mathrm{D}$ simulations with a microchannel width of $2 \mathrm{~mm}$ in Table 2 . The results show that there is a notable difference between normalized values of pressure and temperature for the cases of using $2 \mathrm{D}$ and $3 \mathrm{D}$. These results motivate performing simulations in $3 \mathrm{D}$ despite the significantly longer computation times.

\section{RESULTS AND DISCUSSION}

Figure 2 shows the pressure drop along the mid-line (Fig.1) for $0-8 \%$ volume concentrations of PCM particles. First, a fully developed flow profile was obtained by iteration, where the flow outlet solution was input into the flow cell five times with no heating. Once the flow profile became fully developed, the heating was initiated. The pressure drop along the length of the microchannel length is a result of frictional losses from the wall shear stress and the drag forces due to the interactions between the particle and the carrier fluid in the flow field. The particles in the working fluid influence the momentum as a result of the drag force and local acceleration. However, in the modeled case, the size of the particles is small $(1 \mu \mathrm{m})$ and the channel length is short, such that the drag and particle acceleration have a negligible effect on the pressure drop as shown in Fig. 2.

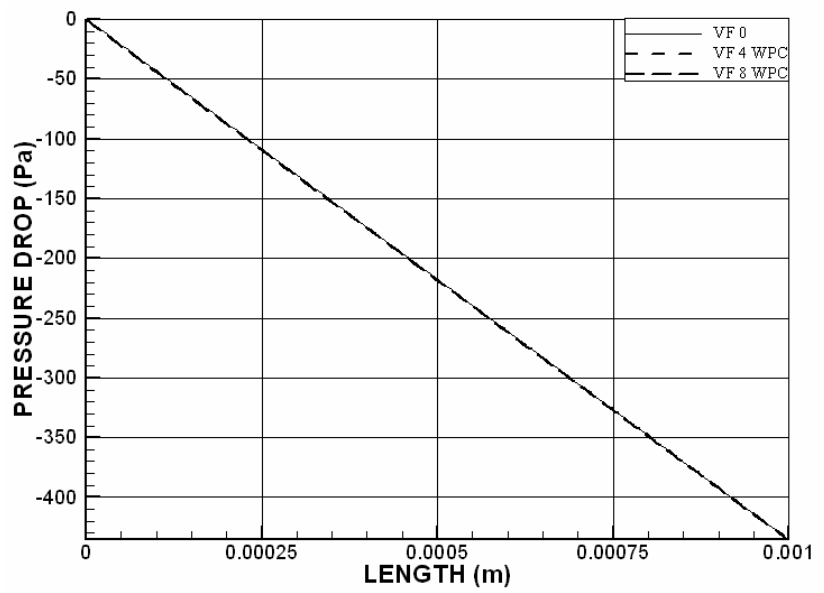

Figure 2.Pressure distribution along the channel length where VF 0, VF 4 WPC, and VF 8 WPC represents $0 \%, 4 \%$, and $8 \%$ volume fraction of particles, respectively.

Figure 3 and Fig. 4 show temperature contours along the channel length while Fig. 5 and Fig. 6 show temperature contours across the channel cross-section for the cases with and without the presence of PCM particles in the carrier fluid, respectively. The temperature increases in the channel towards the channel exit due to heating from the channel bottom wall. Although, the friction in the shear layer contributes to temperature rise, the temperature increase in the channel is primarily a result of external heating of the working fluid. Consequently, the major contributor to the temperature increase is the external heat input to the channel. Moreover, increasing the concentration of PCM particles contributes to decreasing the temperature in the channel towards the channel exit, which is attributed to the latent heat associated with phase change of the PCM particles. This effect is more significant at higher concentrations of PCM particles, as shown in Fig. 7. These results indicate that improvements in thermal storage capacity of the working fluid are possible by increasing PCM particle concentration with minimal pumping power losses.

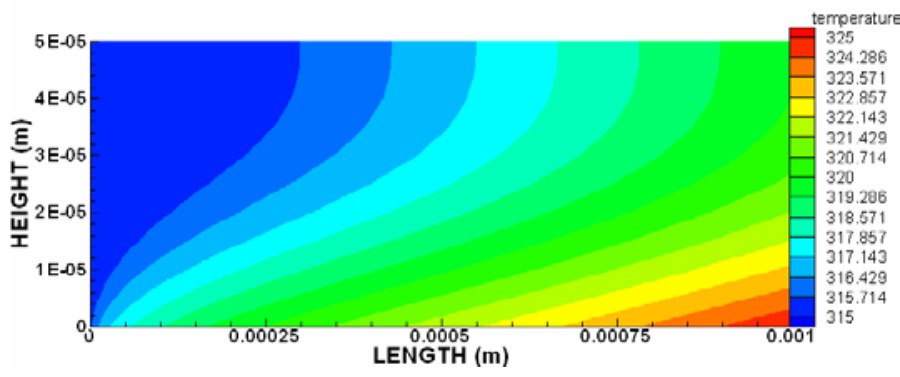

Figure 3.Temperature contour along the channel length for $0 \%$ volume fraction of particles. 


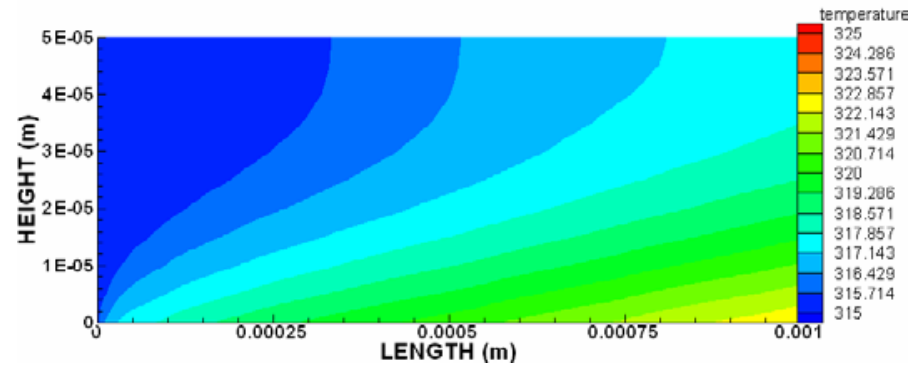

Figure 4.Temperature contour along the channel length for $8 \%$ volume fraction of particles with phase change.

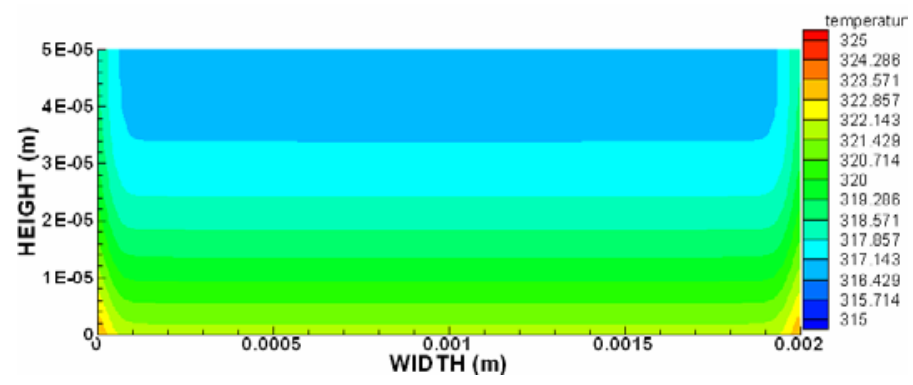

Figure 5.Temperature contour across the channel cross section for $0 \%$ volume fraction of particles.

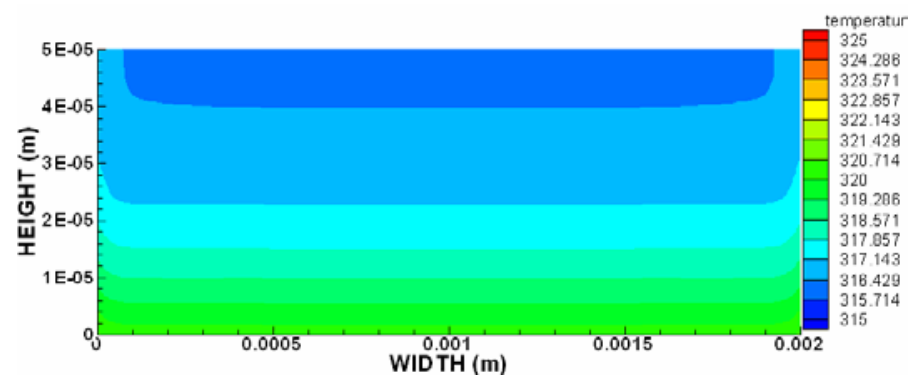

Figure 6.Temperature contour across the channel crosssection for $\mathbf{8 \%}$ volume fraction of particles with phase change.

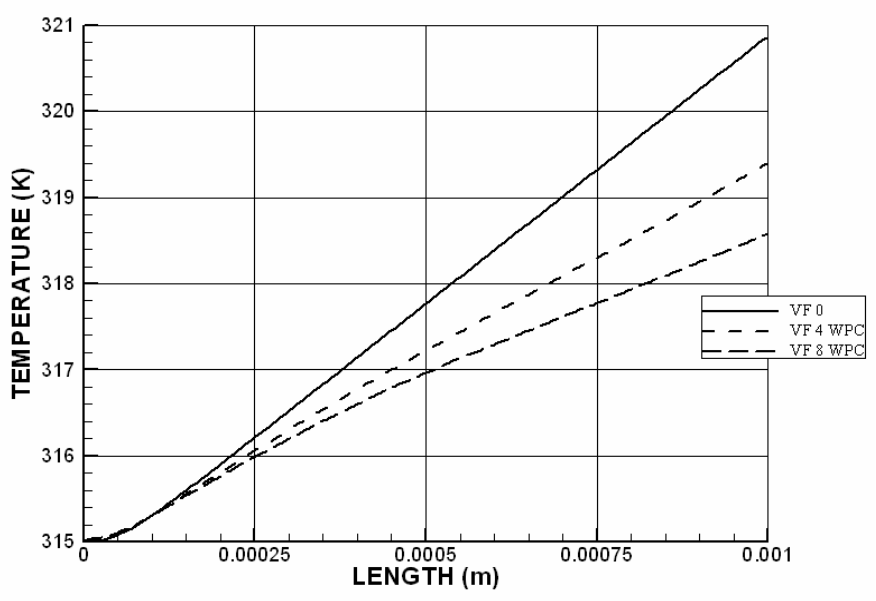

Figure 7.Temperature along the mid-line where VF 0, VF 4 WPC, and VF 8 WPC represents $0 \%, 4 \%$, and $8 \%$ volume fraction of the particles, respectively.

\section{CONCLUSION}

We investigated microchannel flow with water in the presence of lauric acid PCM particles. The flow field and heat transfer in the channel were simulated using a 3D model. The presence of PCM particles of $8 \%$ only slightly increased the pressure drop along the channel length by $0.053 \%$, where the main contributor to pressure drop is frictional losses in the shear layer. The heat transfer performance, however, was improved, due to the relatively small temperature changes during phase change of the microparticles. The study shows that increasing the concentration of PCM particles improves the heat storage capacity of the working fluid through the phase change of PCM particles. This work provides a starting framework for future studies of different PCM particles and carrier fluid properties, different particle volume fractions, and more realistic microchannel geometries.

\section{NOMENCLATURE}

$\begin{array}{ll}C & \text { Specific heat, } \mathrm{J} /(\mathrm{kg} \mathrm{K}) \\ d & \text { diameter, } \mathrm{m} \\ E & \text { Energy, } \mathrm{J} \\ k & \text { Thermal conductivity, } \mathrm{W} /(\mathrm{m} \mathrm{K}) \\ L & \text { Latent heat of melting of particles, } \mathrm{J} / \mathrm{kg} \\ p & \text { Pressure, } \mathrm{Pa} \\ T & \text { Temperature, } \mathrm{K} \\ T_{\text {in }} & \text { Temperature at inlet of control volume, } \mathrm{K}\end{array}$


$T_{\text {out }} \quad$ Temperature at exit of control volume, $\mathrm{K}$

$T_{m} \quad$ Average melting temperature, $\mathrm{K}$

$T_{r} \quad$ Reference temperature taken as $298 \mathrm{~K}$

$\vec{v} \quad$ Velocity, $\mathrm{m} / \mathrm{s}$

$v f \quad$ Volume fraction of particles

$\rho \quad$ Density, $\mathrm{kg} / \mathrm{m}^{3}$

$\tau \quad$ Shear stress, $\mathrm{N} / \mathrm{m}^{2}$

$\mu \quad$ Viscosity, Pa.s

( ) $\quad$ Carrier fluid

( ) Particle

\section{REFERENCES}

[1] Kondle, S., Alvarado, J.L., Marsh, C., Kessler, D. and Stynoski, P., 2009, "Laminar Flow Forced Convection Heat Transfer Behavior of a Phase Change Material Fluid in Microchannels," Proceedings of the ASME 2009 International Mechanical Engineering Congress \& Exposition, 13-19, Lake Buena Vista, Florida, USA.

[2] Hu, X., Zhang, Y.,2002, "Novel Insight and Numerical Analysis of Convective Heat Transfer Enhancement With Microencapsulated Phase Change Material Slurries: Laminar Flow in a Circular Tube With Constant Heat Flux," International Journal of Heat and Mass Transfer, 45, pp. 31633172.

[3]Xing, K.Q., Tao, Y.X., Hao,Y.L, 2005, "Performance Evaluation Of Liquid Flow With PCM Particles In

Microchannels." Journal of Heat Transfer, 127, pp.931-940.

[4] Sabbah, R., Farid, M.M., Al-Hallaj, S.,2008, "MicroChannel Heat Sink With Slurry of Water With MicroEncapsulated Phase Change Material: 3D-Numerical Study," Applied Thermal Engineering, 29,pp.445-454.

[5] Chen, B., Wang, X., Zeng, R., Zhang, Y., Wang, X., Niu, J., Li, Y., Di, H., 2008, "An Experimental Study of Convective Heat Transfer With Microencapsulated Phase Change Material Suspension: Laminar Flow in a Circular Tube Under Constant Heat Flux," Experimental Thermal and Fluid Science, 32, pp. $1638-1646$.

[6] Wang, X., Niu, J., Li, Y., Wang, X., Chen, B., Zeng, R., Song, Q., Zhang, Y., 2007, "Flow and Heat Transfer Behaviors of Phase Change Material Slurries in a Horizontal Circular Tube," International Journal of Heat and Mass Transfer, 50,pp. 2480-2491.
[7] Yamagishi, Y., Takeuchi, H., Pyatenko, A.T, Kayukawa, N., 1999, "Characteristics of Microencapsulated PCM Slurry as a Heat Transfer Fluid." AIChE Journal, 45 (4), pp.696-707.

[8] S.V. Patankar, Numerical Heat Transfer and Fluid Flow, Hemisphere Publishing Company, Washington, DC, 1980.

[9] Product Documentation, Fluent Inc. 